\title{
High-risk, Critical Decision Making under Time-pressure: Some Parallels and Learning from Split-second Choices Made in Extreme Adventure Sports
}

(Working Draft)

\section{Lt. Col. Ravindra Singh Bangari, Fellow IIM-B}

\begin{abstract}
In a world where crisis, surprise and change is the new norm, everyone from professional manager down to the layman is keen to understand how to make quick decisions under emergent situations. This article, employing self-reflective analysis of critical incidents, describes the author's personal experiences from the field of adventure sports categorized as high-risk, critical decisions, involving split-second choices — made while sky-diving and flying between 10,000 feet down to 10 feet above ground level - to trace the mental cognitive processes from a decision maker's perspective. This is used to discuss and establish a practitioner's operational framework of high-risk, critical decision scenarios, drawing upon established theories and frameworks from cognitive and psychological decision research.
\end{abstract}

\section{Keywords:}

Critical decision making; high-risk environments; time-pressure; extreme adventure sports; mindfulness; practitioner-oriented 


\section{High-risk, Critical Decision Making under Time-pressure: Some Parallels and Learning from Split-second Choices Made in Extreme Adventure Sports}

There is general curiosity among people to know how certain class of professionals at

work, especially, experts, make split-second, critical decisions on which, sometimes, lives could well depend. Professionals may want to understand this in order to make better decisions themselves in similar situations. While split-second choices are being made all around us in some ways all the while, e.g., in hospitals, on roads, and in our daily routines, there is a special lure to how high-risk adventure sportsmen face such critical situations that they are confronted with. This paper reflects on these split-second decisions in a specific critical context from a practitioner's perspective and seeks to draw out learning that may be of interest and utility in the wider professional context.

\section{Background and Past Research}

To set the context, I list out key research streams that inform this paper's analysis. The study of judgment and decision making can be traced back to the 1940s (Barnard, 1938; Simon, 1947, 1955, 1959, 1979; March \& Simon, 1958a, 1958b; Neumann, \& Morgenstern, 1944), through seminal advances made in the 1970s and later (Kahneman and Tversky, 1979, 1984; Tversky and Kahneman, 1973; March, 1997; Mintzberg, 1973; Mintzberg, Raisinghani, \& Theoret, 1976; Weick, 1979; Weick, Sutcliffe, \& Obstfeld, 1999), that have informed the field. Currently, the study of decision making is mainly focused on cognitive and social psychology, and studied in terms of human information processing (Koehler \& Harvey, 2004, as cited in Bar- 
Eli and Raab, 2006). In contrast, Bar-Eli and Raab (2006) report, "Almost none of this has been reflected in the sport psychology literature". In sports specific decision making, recent focus has been on individual cognitive processes as applying in the ecological context (Araujo, Davids, \& Hristovski, 2006; Johnson, 2006). General opinion converges to beliefs that individual understanding and responses to a dynamic context with multiple variables can lead to complex decision making behaviours that need to be studied (Araujo, Davids, \& Hristovski, 2006; Johnson, 2006).

Interest in experiential outdoor activities for individual, team and organizational learning and development has been evident over the last few decades. Kolb's $(1974,1984)$ research and findings have led the way in recent times, taking up from earlier pioneers. Currently, many business schools have programmes that are centred around experiential learning, such as, Wharton's Leadership Ventures (n.d.). Interest in application of decision making theories and frames to real-world outdoor situations is exemplified by the numerous research applications to the Mount Everest disaster in 1996, when five climbers led by two of the world's leading mountaineers perished in a storm on the slopes of Everest on May 8-9, 1996 (Elmes, \& Barry, 1999; Elmes, \& Frame, 2008; Kayes, 2004; Roberto, 2002; Tempest, Starkey, \& Ennew, 2007, amongst others).

This paper looks at safety, reliability and quality of decision making in crisis in extreme adventure sports, seen from an integrative practitioners' perspective. While numerous anecdotal accounts and individual experiences are available relating to the specific context of "parachute jumping and skydiving" that is investigated here, however, even as the sport has developed over the last few decades, it has remained a niche, specialized activity. Hence, there are few systematic studies into critical decision making in this domain so far. This could partly be 
explained by the nature of the pursuit, which requires both a good understanding of technicalities involved, as well as a closely integrated relationship with this specific adventure sports' community.

One line of thinking that holds promise with regard to understanding this context is 'fast and frugal' heuristics (Gigerenzer, Todd, \& the ABC Research Group, 1999) that has been used to explain some routinely-employed, but computationally complex, activities on the sports field. Activities explained are catching a ball in the field, avoiding collision course, predicting the winner, etc. (Bennis, \& Pachur, 2006; Marewski, Gaissmaier \& Gigerenzer, 2010). Since this class of heuristics emerges from past experience in the domain, there is increased likelihood that they apply better to situations normally encountered, e.g., "within the envelope of one's experience". We will see how this concept applies to high risk decision scenarios discussed here. We also explore learning from certain other domains which show similarity and convergence in terms of their end-objectives, namely, findings from NAT and HRT theoretical literature (Perrow, 1984; Rijpma, 1997; Shrivastava, Sonpar, Pazzaglia, 2009; Weick, 1979/1969, 1993; Weick et al., 1999).

\section{Objective and Method}

The objective of this reflective paper is to review critical experiences of an adventure sportsperson applying reflective analysis, to draw out some parallels and learning from splitsecond choices that may need to be made during such pursuits. In taking the leap from personal to wider generalization, I apply reflective analysis, that is shaped by adventure community-wide culture and norms, through my own experience and personal interactions within the community (bounded within the military services' operational environment), over a decade and half. 
Operational and functional norms prevailing within specialized professional communities, studied through autoethnographic accounts of incidents and experiences within these communities, can provide useful insights and indicators to understanding the larger context (Rowe, O'Brien, Rouse, \& Nixon, 2011). Rowe et al. (2011) discuss the advantages and challenges relating to use of autoethnography as a robust research method, stating, "The autoethnographic story is not, therefore, merely a tale. It provides access to data otherwise not available and represents a "provocative weave of story and theory" (Cohen, Duberley, \& Musson, 2009, p. 233) that potentially can be generalized to others' experiences and to theory." Gene Rochlin, one of the pioneer "high reliability" researchers with Todd LaPorte and Karlene Roberts (1987), makes a relevant observation when he brought out the difficulty and limitations of their own (the researchers') role, saying that they needed to keep the expectations of the subjects of their study grounded during their research; he specifically mentions that Todd would "most carefully explain how we could never really learn enough to fully understand the complexity and intricacies of the operations and operational environment in detail. The most that they could expect would be for us to point out the more general role of organizational behaviour and structure, and perhaps, a few specific things that might prevent future errors." (Rochlin, 2011: 15) This viewpoint buttresses the importance of the participant perspective in these specialized endeavours to draw meaningful learning. In this first-person reflective piece, I take the view that individual cognition and the specific ecological context needs to be studied to understand decision making process in extreme adventure sports' domain (Araujo, Davids, \& Hristovski, 2006; Johnson, 2006). Specific organization-wide cultural norms and behavioural tendencies prevalent in specialized groups are 
key to deeper understanding. I have covered these below through my own experiences in order to make these activities clearer to any first-time observer.

I first describe certain "critical incidents" (Flanagan, 1954; Klein, Calderwood, \& ClintonCirocco, 1986; Lipshitz, Klein, Orasanu, \& Salas, 2001) I have faced in my operational experience while engaged with these extreme adventure sports, and then apply self-reflective analytical techniques to draw out my learning and sensemaking process (Weick, 1979/1969, 1993; Weick et al., 1999) through these experiences. In this analysis, I also discuss how one prepares for these contingencies; what's the thought process that one may go through when faced with such a situation; why people make seemingly inexplicable risky decisions (and what they do to cover themselves as a back-up safety mechanism); and, finally, analyze why sometimes things go horribly wrong. I conclude with some takeaways from these high-risk, critical decision moments in adventure sports for professionals in other domains. In the discussion section, I also relate these experiences and learning to some prevalent theories and, in doing so, try to deconstruct these theories for practitioners in field.

I was introduced to my pursuit of adventure during my service in the Army's Parachute Regiment. As a young enthusiastic person, you want to try out all things in world and, most of this time, one is not scared of the risks involved. As part of an elite group of individuals that take pride in pursuit of adventure, ${ }^{1}$ it is mostly a matter of what opportunities come your way in those initial years. While there are some crazy sort who don't even think about the consequences and just jump right into it, let me add that I wasn't part of them and I certainly did try to think over what the risk was, why I should face that and what I could do about it, before I jumped into action! So, while there was this adrenalin thing going on, there was also some hard thinking that

\footnotetext{
${ }^{1}$ Read the brief article, The Paratrooper, to get a feel of a paratrooper preparing for a mission, exiting from an aircraft into the operations zone and getting on with the night's work, at The Havok Journal, http://www.havokjournal.com/culture/the-paratrooper (accessed on 15 May 2020).
} 
I was doing during all my adventure pursuits that I describe here (e.g., refer the notes that I took while participating in these activities at Figure 1). The activities described have a common thread of being aerial-domain based — falling and/or flying through the air. That kind of imparts a sense of urgency and danger to the matter, aligning it with high-risk and critical decisions, to a general observer's understanding.

Insert Figure 1 about here.

I describe these activities and critical incidents in a sequential manner in which they occurred over time, as that would help maintain a sense of perspective and order to my own learning through these experiences. The method I follow is employing a descriptive narrative, interspersed with my own thinking, analysis and learning where they fit in. This, I hope, will allow the readers to journey with me and be able to get a better sense of this somewhat alien domain to most, as I presume.

One obvious challenge and limitation with such autoethnographic accounts of specialized incidents and experiences is testability of the narrator's propositions drawn from one's experiences. In support for some of the key learning that I draw out from the narrated experiences, I would like to mention that the section "Parachute Jump after Recovery" describes an incident akin to a validation trial (or, experiment). The inherent risks were very much present in this controlled experiment and so it can be viewed, in a manner, as support for the underlying thought processes relating to the described experiences. 


\section{Parachute Jumps, Sky-diving and Canopy Malfunction Emergencies}

\section{Initiation and Overview $\left(\mathrm{A}^{2}\right)$}

'You can never forget your first jump, despite how much you prepare for it, mentally and physically, to take it in your stride, and how-so-ever stoic you may be to new experiences in a qualitatively different domain.' I jumped out the first time with a static line parachute from a helicopter at about 1,400 feet. In this case, an anchored static line triggers the canopy deployment and it is just a question of four to five seconds before you find yourself strung below a parachute, suspended in the air, on your way down in full glory (see Figure 2 for a graphic of static-line parachute opening sequence). As I stepped out from the firm floorboard of the helicopter into the vacant nothingness outside, with that momentary churning of my stomach, it seemed that I was going into a slow tumble, something I had not quite bargained for. It was only a few moments, but quite uncontrollable. Mercifully, before it could turn into anything serious, there was a tug on my back and shoulders, and I was being lifted upwards; lo and behold, I was finally floating down free, suspended below the parachute, with just the deceptively silent whistling air for company. You have little time to relish the experience, though, before reality comes knocking soon, as you need to prepare for the landing on ground, with all those instructions for various contingencies going through your mind. Soon you learn another hard lesson in life - that it isn't really possible to get the smooth 5-point landing-roll instructors teach you during the ground training!

Slowly, over a period of time, a jumper begins to understand how exits happen in a static line jump. You also begin to think deeper and prepare your own checklist of points to look out for, for a safe exit and descent. For me, this mental checklist (regularly updated) keeps flashing

\footnotetext{
${ }^{2}$ Identifying alphabet code for critical incidents used in Table 1.
} 
through my mind every time I have prepared for a jump since. There are no heroics; only caution, preparedness and control to be exercised in adventure sports.

Insert Figures 2 and 3 about here.

Some years later, I got an opportunity to do the military free-fall course. One graduates in this from static line to free-fall jumps, implying that you are now more in control of your destiny-in terms of deciding when to actually pull the parachute open; otherwise, you keep falling down free-accelerating till you reach 'terminal velocity', bringing to life theoretical school physics. In a sky-dive, one begins by pulling on the rip-cord to deploy the chute after a small time interval, usually, five seconds. This allows one to get a feel of free-fall without it turning dangerous. I still remember how my body began to tumble even in this brief period, much as I tried to counter and stabilize, keeping hands and legs outstretched in a 'spread-eagle' position (see Figure 3). Familiarizing with a new domain is an experience that must be learnt by doing, thinking and doing again; so, it is good to understand the laws that govern it. It takes a few practice jumps to be able to come to grips with the new environment and be somewhat in control. I faced a few high-risk, critical decisions, just as I was beginning to feel more confident in this environment. Going back to when falling through the air, it is important to remain in control of one's body's 'attitude', as how it is held in a stable position in this phase, so as not to go out of control into a 'spin', when one could even pass out; or hit someone else, by getting too close to others; or encounter an emergency during the deployment of the parachute.

One deploys the main parachute for a safe landing anywhere at 3,000 feet or above, keeping a safety margin. During this process, it is important to be in a stable position, lest the parachute wrap itself around any of the body parts during a tumble, leading to a serious situation.

Deploying the parachute at this height gives enough altitude and time to deploy the reserve 
parachute, in case of main parachute failure. Cases of main parachute failure or malfunction are rather rare-I would put it at less than 0.01 of a percent, but they do happen. Let me recount my own experiences with situations involving this "one-hundredth of a percent possibility".

\section{Main-chute Full Malfunction During Parachuting (B)}

I was into my $12^{\text {th }}$ skydive and I was about getting more secure in my control over the skydive sequence. The initial skydives were made using simpler round canopies, where direction control is achieved with the help of toggles that go up the rigging lines to two small openings on either side to the rear of the parachute. I exited out of the aircraft, fell free and stabilized myself in the spread-eagle position, and began to look out all around me, if all was clear. Glancing at the altimaster on my wrist to note the height, I was also relating to the other skydivers who were below me. There was still time to deploy the main parachute, but one must not depend only on the altimaster, lest it was not functioning - it is important to track by situational awareness of those around you, especially, those below you. At about 3,500 feet, I pulled at my ripcord. For the next few seconds, I kept falling and there was no opening shock on my torso and the shoulders. Somewhat disoriented, I looked at my hands to check if I had actually pulled at the ripcord - yes, it was there in my right hand (see Figure 4). So, what was happening — why had the main parachute not deployed? That "something has gone wrong" strikes you then.

Even as the urgency hits you, you are trying to recollect what needs to be done. You just have a few seconds now. I still could not feel any slowing down, or a malfunctioning main parachute anywhere above me. With this awareness, I again briefly double-checked if the ripcord handle was there in my hand. It was; so, I didn't even know what was happening there-why had the main parachute not sprung up and deployed. I then just discarded that line of inquiry (my 
applicable repertoire being limited then), focusing on what needed to be done under the circumstances - prepare to deploy the reserve. Going over the sequence in my mind, I braced for the deployment of the reserve, moving my hand to the reserve's ripcord which was to my front, below the stomach, as I fell face-downwards. As I tugged and pulled it away, sideways and outwards, I remember this thought, "Well, that's all I can do-now, let's see!" With almost a crunching pull to the small of my back, the reserve parachute opened and yanked me upwards from my freefall (see Figure 4). What a relief it was! I then saw that the main parachute's canopy had come out of the bag on my back and was now dangling alongside and below me, halffluttering in the air. I immediately remembered what to do and quickly reeled it in between my two legs, lest it partially blow up now (i.e., partly-deploy) and cause the reserve to collapse due to interference with the slipstream-leading to a new disaster-surely, I did not want to get into that!

Insert Figure 4 about here.

On ground, conversing with the instructors, I reiterated that I had felt absolutely no shock or pull from the main parachute, when I pulled the ripcord. The only possibility that remained was that the spring of the drag parachute was weak and may not have sprung up enough and so it remained stuck inside the slipstream above me, as I was falling, thus causing the main parachute to fail. Later, once the reserve deployed, it could have just fallen out alongside me. This was something new I learnt that day, which had not been covered in the training till then, so to say.

\section{Main-chute Partial Malfunction During Skydiving (C)}

Further still into the course as we were became more experienced in skydiving, we graduated to the more advanced rectangular ram-air design canopy. This permits higher 
manoeuvrability, but also increases the forward landing speed which needs finer control for a safe touchdown. The system of release of the reserve parachute is slightly different in this design. In contrast to the round canopy, where one deploys the reserve with the main remaining in whatever state it has deployed to (or otherwise), in this advanced canopy system, the sequence of deployment of the reserve parachute is that it first releases the main parachute above and away from the skydiver, and only then it pulls out the reserve parachute to deploy. Basically, you let go of the malfunctioning main parachute, before you deploy the reserve in this case. It is all fine in theory, however, execution holds some challenges. A number of jumps down the line, one day I found myself in a tricky situation. After I had deployed the main parachute at about 4,000 feet, I felt some violent swinging as the canopy developed overhead. As I looked up at the canopy, something didn't seem right— - the cells were not fully inflated and developed. The toggles running from behind the shoulder straps to the parachute wing did not appear to be clear, and so, were not effective in providing directional control.

I soon realized that I was turning slowly to the right. I tried what I could do with the toggles, pulling them down and releasing them over a few times so as to free them, but to no avail. The reality was now beginning to hit me. I had an emergency. I was continually turning right, albeit at a slow pace as it seemed to me then, but I was unable to control the turn. This effectively meant that I had no control over the canopy. This meant that I would be carried where the canopy would take me and I would still be turning while landing, which could break my legs or otherwise during the landing, depending on the turning speed. ${ }^{3}$ I wondered if the situation called for a reserve deployment. This also meant, as my mind raced forward, that I would be releasing the main canopy above me before the reserve deployed. So, I was faced with a hard choice about

\footnotetext{
${ }^{3}$ After landing, an instructor told me that the situation could have been much worse. The turning movement's speed could have increased and even put me into a dangerous, life-threatening spiral. I did not know this then, though, while I tackled the above emergency.
} 
something that had seemed abstract so far. Was it advisable to let go of "some hope" that I held onto now, in the expectation that the reserve parachute would deploy correctly? Remember, that small fraction of a one percent chance I mention above. This was live for me now. Even though I had knowledge about basic physics and probability that the chance of a reserve malfunction is much, much lower (due to it being activated at a much lesser descent rate in contrast to the main at about terminal velocity), it was not much comfort to me that I was letting go whatever concrete hope I held onto right now! Seconds ticked away and I needed to make a decision. I was continually looking at my altimaster, monitoring my descent. Even though I was not to know then, I was told later by ground-based observers that my speed of right turns was increasing and they feared I could go into a spiral, which would get much more dangerous. I finally decided that I needed to take the chance and not risk getting injured on landing, comforted by cold physics and probability that things would work out well. With a sinking feeling in my stomach that this just needed to be done, I pulled the ripcord of my reserve at about 2,700 feet (see Figure 5). I could actually sense all that was expected to happen in the operating sequence above me. Finally, the reserve deployed correctly and I was safely on my way down.

Insert Figure 5 about here.

In discussions on ground, it was surmised that the rigging lines of the main canopy may have got entangled with the canopy and each other, resulting in a loss of control and a continual slow right turn. Ground observers felt that the turns were beginning to increase in speed and they were concerned I was taking too long to decide. 


\section{Powerchute Flying in High Altitude: A Flight Emergency (D)}

Some years later, I had an opportunity to take up paragliding. From there, it was progression to flying a single-engine powered, collapsible wing glider, called Powerchute. This flying machine had a rectangular ram-air canopy (as of the skydiving chute described above) and it was very powerful flying at altitudes ranging upto about 4,000 feet above sea level. I remember flying in the proximity of and over the TV tower area in Bangalore, close to our training location (see Figure 6). There was some doubt in one's mind about the manufacturer's specifications as it appeared to carry a comparatively heavy engine and we weren't too optimistic about the likely glide ratio in case of an engine failure; so we kept a safety margin always while flying. In 1998, I was to participate in flying this machine in an expedition in Ladakh (altitude about 10,600 feet). We were just going to try and fly these Powerchutes at those altitudes to check out their performance. As we flew-in in an air-force transport aircraft, whose pilot happened to be a course-mate back during training at the academy (National Defence Academy, Khadakwasla), I remember he telling me that sometimes even they felt buffeted by the strong winds when coming in to land at Leh airfield; early mornings was generally the best time and afternoons pretty bad for flying due to the high winds later in the day there.

Once we had acclimatized and checked out our machines, we were ready to try to attempt some flights in the vicinity of the airfield. We had two machines and we found that one of them was able to take-off in the very first attempt itself. I was on the other machine that wasn't able to get off the ground, despite my gunning the engine as much as I could. I made a couple of attempts, before I realized that what I feared was true - this machine was for some reason under-powered compared to the other one, as earlier noted during the trials and preparation at lower altitudes. So, once the other pilots had done their flying with the first machine, I queued up for it, saying 
that I would just try my hand at it once and fly one or two quick circuits to understand why the one I had earlier attempted wasn't able to take-off.

Insert Figures 6 and 7 about here.

By now, the sun was well up and temperatures were slowly rising, but it still seemed alright for a quick flight to me. I lined up on the tarmac and revved the engine. The machine began moving forward and then took off. I was off the ground and now to the task of gaining height and doing a quick circuit as I had planned to. At this stage, it seems the machine did not gain height as quickly, or at all beyond the initial burst, as it should have; and, while I remained focused on controlling the direction and seeing the clearance off the ground, I did not realize the passage of time at that moment when I was being quickly carried to the perimeter of the airfield itself. My attitude, as I was seated on the machine, would also have hampered clear forward visibility and perspective about where I was headed, as I was leaning backwards into the seat and my legs and the front wheel were raised upwards in front of me (see Figure 7). It seems I got involved in these smaller issues and lost a sense of where I was headed, occupied as I was with controls and trying to look both forward and below. I do not remember what went wrong and when it began to become dangerous instead. I just remember seeing the barbed-wire fencing atop the airfield's boundary wall looming up right in front of me and I knew in that instant that however much I gunned the engine, I possibly may not clear that, but there wasn't anything else I could do better then, as it was so close: I just kept going, foot on the pedal, hoping to clear the wire fencing by a miracle. I ran out of luck that day! I must have crashed into the wire fencing and come down, taking the impact on my left side, crushing the left leg in the bargain; I did not know, but luckily, I just about held on to life, against a barbed wire strand pulling against my neck, as I was found slumped forward by others who had rushed after me. 


\section{Parachute Jump after Recovery (E)}

There was a long period of recovery that followed. There were stints of months in hospital and surgeries followed by rehabilitation, etc. Finally, I was out of the hospitals in whatever best shape I could be put in. It wasn’t good enough for active service, so I was given medical discharge. Thereafter, it was a long haul trying to regain some modicum of fitness to the extent feasible.

In 2009, about 11 years after my accident, I was again toying with the idea of doing a parachute jump. I don't think I had any heroics in mind, nor was I going to receive any kind of incentive for doing that; it's just that as I had worked on my physical fitness over the past few years, overcoming difficulties along the way, I was beginning to develop more confidence again in what my body and I could do (as also what I couldn't do). I had taken to swimming regularly and walking as much as I could, and, it seemed to me that it would be a perfectly safe proposition, under controlled circumstances, as is normally the case during Veterans' Reunion jumps. I mentally went over the sequence and the implications many times just to be sure that I was right in my thinking. I also checked out my body's ability to take the impact of a landing by jumping up and down, and the ability to cushion my fall by immediately rolling upon landing, using the 5-point roll sequence (remember that!). Once I was sure of this, I went forward soon as an opportunity presented itself. It was at a Regimental Re-union where Veterans are invited too to parachute jump alongside serving personnel. When I declared my intent to jump on the occasion, some of my friends and well-wishers seemed sceptical and advised me not to be serious about it. But, go I did. It was the same feeling of sweat, cramps and aches as the parachute is strapped tight to one's body! I loosened up my body and kept it warmed up to remain agile. Mentally, I 
was busy too, going over each step in my mind and rehearsing for what was to come up next. Everything went off as it normally does on a good day. As I moved forward in the queue to exit, and the lights came on 'green' to go, I continued my deliberate shuffle towards the exit ramp, maintaining my balance, till it was the moment to step out, taking a controlled leap, and tucking myself into a crouched compact shape. The familiar jerk on the shoulders and the upward pull, and soon I was floating down serenely. I looked around, checked to make sure all was ok, pulled at the toggles of the parachute to change direction into the wind and controlling to move closer towards the centre of the drop-zone. Then, it was time for the landing impact and roll, which went the way it normally does — not as in practice, but ok nevertheless! A few months later, I got another opportunity to test my beliefs and preparation technique in one more parachute jump, which also went off successfully, thereby, in some measure, validating the crux of my selfreflection and learning.

\section{Account of a Tragic Mid-air Parachute Air-Accident (F)}

Let me recount a related incident that I was eye-witness to, which validates some of the learning points we are referring to. In June 1990, I was part of a company group airborne drop exercise that was being held in high altitude at Stakna in Leh. I will not go into the details of the incident, but when the parachute jump was being carried out from a three-aircraft 'vic' formation, one of the aircrafts at the tail encountered turbulence and wasn't able to maintain its course. As it banked inwards, it began to plough into the jumping personnel from the leading aircraft. Of course, one didn't know that then. I, incidentally, was up in mid-air right then, having jumped out from the leading 'vic', while this was the following 'vic' formation. Looking up, I could make out sharp sound of a rustle and something like white powder spreading outwards 
from about there. Shortly thereafter, I could notice a few canopies just fluttering away, falling, but not opening fully. Two of these flailing, fluttering canopies managed to deploy the reserve chute and slow down; not so, the others. On landing, the situation came clear and one learnt about the casualties as the momentarily out-of-control aircraft's propeller began to cut into the tops of the canopies just as they had opened and/or were still opening. Luckily, both those who managed to deploy their reserves were from the same battalion as I, and I was able to talk to them in detail, trying to understand what had happened.

What emerged was a picture of how they comprehended the situation they were in and how they responded to it. As they jumped out of the aircraft, they tucked themselves into a crouched position, hunched over forward, waiting, as we do, for the opening shock of the parachute. They said that when they felt the shock, they could not make out what exactly was going on, but as they turned their heads up to see, they could notice that their parachutes were not fully ballooned; instead, something was wrong as they were falling down faster in an unstable manner. They soon realized that they were in an emergency "candle" situation, where the parachute does not open fully and just flutters on top above like a candle, unable to open forced by the wind rushing in due to some malfunction. Once this realization struck them, they remembered what had been drilled into them for such an emergency. In this case, it was clear that they needed to deploy their reserve parachute (at their state of training), which they did as per their training. In fact, both these individuals were not very experienced jumpers and they seemed to have only a basic idea of the parachute opening mechanism, but it was their rigorous training that came to their aid to help them decide what to do in this emergency. This, however, is still not the full picture there. We do not know why two other individuals, who faced the same situation, were not able to respond similarly. I cannot hazard an answer as facts were not very clear then. Were they 
even conscious as they fell down with a major main parachute malfunction? Did the shock and/or impact of the aircraft's propellers going through their parachute cause them to pass out? Or, did they just panic, not realizing their situation and what they needed to do? We have no answers to these questions, complicating the analysis.

\section{Lessons for Decision making from High-Risk Adventure}

While the above narration of some critical instances of decisions involving elements of split-second choices is by no means extensive in scope, yet we can glean some useful learning from the deeper processes and linkages that appear to be at work behind these instances. There is an organizational processes' structure and prevalent culture that shapes training of this high-risk activity, which leads to specific techniques and methods we see at play here. There is also a professional environment that exists in these skilled organizations that are involved in these activities as their core speciality. Finally, there is the individual mind that prepares to partake in these activities and readies itself, both psychologically and technically, for the inherent challenges that the task involves. Hence, the critical incidents and responses thereto described above are not entirely unique to an individual; these could well be the experience of others operating alongside in this professional environment, which allows us to make some generic observations here.

So, let us see what can be useful pointers for others likely to face similar situations. I have already given some insight into the cognitive process by articulating my thoughts as I faced these situations in real-time. I will now try and smoothen over the gaps to present an operative practitioners' framework that appears relevant and critical in my view, and, hopefully, is useful 
to others too. Table 1 presents a mapping of learning highlights from these critical incidents with key factors identified for decision making during high-risk adventure discussed below.

Insert Table 1 about here.

\section{Relevance and Context}

I, first, make the case that this learning about high-risk, critical decisions would apply to anyone in a similar situation, with about the same approach to training, practice and emotional mind-set as discussed here. I do not categorize myself as an expert by any parameter on any of these adventure activities; merely an enthusiast, who was keen on trying all these exciting things and, importantly, learning while at it. Experts have experience going into hundreds and thousands of jumps or sky-dives. Instead, I argue that this very contrast actually makes my experience more relevant broadly, because these are the kind of situations that could be faced by anyone just beginning to participate in adventure sports, or similar risky situations at their jobs, and elsewhere. Beginners in any similar field of endeavour need guidance and a greater awareness of the need for 'mindfulness' in these situations, so that they would be better prepared to handle such emergencies, or, at times, perceived emergencies, that they may not have an answer to. The learning herein, if effectively transferred to these individuals, would be most useful to them when they need it. As they pick up experience and their own learning curve deepens, they would then be proficient enough to develop their own safe routines-which is a must and an underlying theme of this paper.

As my status in these adventure sports falls in the category of a beginner, this also means that I made mistakes and some wrong judgment calls. Perhaps, I was plain lucky in some instances, but, nevertheless, came out with hopefully a better sense of the game. I am not denying that my 
description could be biased or even skewed to some extent, limited as it would be by my thenworldview. This process of self-discovery and establishment of a safe individual routine, in an organizational culture based on deeper understanding of key linkages, is important.

\section{Key Factors during High-Risk Critical Decision making}

Let's, first, identify the factors that have a significant influence over how one reacts to such critical situations. These come across from the above description of incidents and reflection to be: (1) training, especially, in the preparatory stage, and continuing thereafter; (2) depth of exposure and understanding of domain expertise; and finally, (3) deep emotional involvement with the domain, i.e., the specific adventure activity. All of the preceding indicates the necessity of a well-grounded, safety-oriented training procedure and an open-minded, passionate learning environment. I elaborate these factors below by breaking them up into more comprehensible action points for those wanting to apply the learning from the field of high-risk adventure sports to their own critical decision making endeavours.

\section{Good Drills and Practice}

Good drills, that are based on collective learning and accumulated expertise, are a must for anyone just starting out. They provide one's mind a framework to think around and grapple with in an unfolding situation, as also throw up some instant options or responses in face of developing situations that are not commonly experienced. The participants must also appreciate why these drills make sense, so that they keep with the drills. This will come about with constant communication and interaction, as happens during one's experience on the basic parachuting 
course. This may have been why the two troopers interviewed by me (mentioned above in F) managed to come out safely and survive after the mid-air accident. As they would have counted, "One thousand, two thousand, .... five thousand", and then looked up to check their canopies to find that something was not quite the same as expected, their minds would have tried to figure out what was happening. In those fleeting seconds, they would have grappled with "What next?", till they possibly recalled their teaching and realized that it was time to pull out the reserve chute "now". Good drills are such that they are most effective even in an emergency-you don't need to think too much. These are powerful, "If so ..., then this ..." rules for a beginner confronted with an expected emergency scenario. Needless to add, these must be carefully reviewed periodically and updated in view of new learning and associated changes with time. A close analogy is that of flight "checklists", which if not up to date, can lead to disastrous consequences, e.g., recent Boeing 737 Max crashes in 2018 and 2019 (Campbell, 2019). However, in the two cases of canopy malfunction that I faced, I had little more time and therefore my mind occupied itself with thinking through the options available more deeply to make a choice. It's good that I had set myself an outer time and altitude limit by when I needed to decide either way; otherwise, I could have remained torn between doubts, choices, and ultimate fear, till it was too late.

\section{Deep Domain Knowledge}

Along with drills and practice, the need for deep domain knowledge is almost a given for anyone wanting to make correct decisions, in any crisis situation. One may be lucky a few times, but that's about it. Deep, domain knowledge is essential to help one resolve new problems. Decision making research indicates that what we call "gut" feeling or intuition is most likely 
backed up by deep domain knowledge, years of experience and practice (Dane \& Pratt, 2007; Kahneman \& Klein, 2009; Simon, 1987). This is similar to what is employed by chess grandmasters, which comes from accumulated knowledge, pattern recognition and problem solving techniques developed over a long period of time (Chase \& Simon, 1973; Gobet \& Simon, 1996; Simon, 1987). Similarly, Dhoni, then captain of the Indian cricket team in all formats of the game and acknowledged for his on-ground success as a captain, explained his decision making style as follows, "I don't plan a lot and believe in my gut feel. But what many people don't understand is that to have that gut feel, you have to have experienced that thing before." (The Times of India, 2014)

This leads us to an interesting question: how much experience is enough? This is difficult to answer. To put it simply, (a) it is never enough, from one perspective or another, and, (b) it also relates to the degree of difficulty of the situational demands. Depending on the conditions encountered in the operating environment, which could get progressively complex as we advance to more stringent operating conditions, one should have had access to adequate learning experience close to the level of complexity likely to be encountered, if not more. So, there is an element of judgment call to be exercised when trying to set up training standards and prerequisites, such as, what should be the experience level of a skydiver in order to be considered adequate for participation in close formation flying and complex tracking manoeuvres, for example (Burke, 2013a, 2013b).

As I mention above, good drills also involve a lot of interaction and communication. During a basic parachute jump course, rookie participants spend many days together, mostly talking about their upcoming jump experience. Their instructors and peers, who have been through the same experience, are close at hand to share their knowledge, experiences and learning with them. This 
is an important interactive process and I expect this triggers a train of thinking in most individuals concerned, so that each one is better prepared to think through any situation they come to face. What I have described here as applying to the field of adventure sports, is likely to find useful parallels in other critical domains where such decisions may need to be made too. Sustained inquiry and finding meaning of experiences undergone are vital steps in this process (Weick, 1993, 1996; Weick \& Sutcliffe, 2006).

\section{Being Prepared, "Mindfully"}

One of the key facets of a 'thinking' adventure seeker and risk-taker is being prepared for what he or she is getting into. As discussed above, being prepared for what's to come and being conscious of what's happening around oneself at all times, while so immersed, allows an individual to make better informed choices in a critical situation, if it were to emerge. It is akin to 'mindfulness', which has ancient roots in the Buddhist tradition, but discovered more recently (albeit, somewhat differently) by western thinkers and psychologists as applying to the modern organizational context (Weick \& Putnam, 2006; Weick \& Sutcliffe, 2006). It is "best understood as the process of drawing novel distinctions" (Langer, \& Moldoveanu, 2000), said to "[entail] a unique way of looking at the world" (Shrivastava, Sonpar \& Pazzaglia, 2009) and is exercised through active refinement of existing categories, their continuous updating, and a more nuanced appreciation of the context and how to deal with it (Langer, 1989; Langer, \& Moldoveanu, 2000). Weick, Sutcliffe, \& Obstfeld (1999) extend this model of individual mindfulness to the group level to explain the underlying bases of high reliability in organizations — by identifying five relevant cognitive processes that lead into it, which they use to develop their model of mindful organizations (also Weick \& Sutcliffe, 2006). 
As I recount in the two canopy malfunction instances above, I think I was better prepared for what was to come as a result of this aspect of mindfulness. Some of the thinking had already been done on the ground during my interactions and efforts to understand and learn about the domain-related technical intricacies till then. All I needed to do then was to initiate a quick mental-checklist countdown about what exactly was happening to arrive at what I needed to do, as recommended in such an instance. Being 'mindful' about what one is going through helps recognize the limits of freedom available, as well. One of the things uppermost on my mind in these two situations was the altitude, and consequently, time, I had to make a decision in response. Being mindful involves many things in parallel, e.g., alongside the preceding concerns, I was even sub-consciously double-checking my height against the altimaster on my wrist and visually against the other skydivers and the ground below. I did this instinctively here, but this method of application comes close to how high reliability organizations operate (Shrivastava, Sonpar \& Pazzaglia, 2009; Weick \& Sutcliffe, 2006; Weick, Sutcliffe, \& Obstfeld, 1999). Continuous updating of current reality, matched with one's repertoire of experience, understanding and capability, helps to throw up better suited options that could just help to mitigate an unfolding crisis.

Novice adventurers must be careful about changes in context, or the environment, against what they have been accustomed to till then. A powerful example is what I faced flying the Powerchute in the rarefied atmosphere of Leh. Despite the cautionary note from my friend, the pilot, as he flew me into Leh, about the treacherous weather there, we were, nevertheless, lulled into thinking 'all's well' in the clear skies that we encountered in our short stay leading up to the day of the accident. There were other psychological factors at work too, in tandem, for example, overconfidence bias (e.g., I have done this many times earlier; what's the big deal?) and anxiety- 
fuelled achievement-orientation bias (How can I be left behind others at this?). Coming together, all these caused me to neglect what were critical differences in the environment, which unfortunately turned out to be disastrous there.

So, being mindful is about being aware of the differences in what the situation holds out right then; or, at least, asking oneself how things may not be what one presumes them to be, and looking out for the small contrarian signals that should not be there as per one's current understanding of the context.

\section{Planning and Preparedness for Contingencies and Options}

In order to be well prepared for any critical contingency in a high-risk environment, there is never enough thinking and preparation one can do towards that. A systematic process to identify likely eventualities — things that could go wrong — along with their appropriate responses, followed by realistic practice and simulation, is the only way forward. This is important in view of two tendencies that are widely noted amongst humans: one is overconfidence bias amongst professionals (Meehl, 1954, 1986; Kahneman, 2011; Kahneman \& Klein, 2009; Shariatmadari, 2015) and the second is the general lack of preparedness for what can go wrong in any situation (Kahneman \& Klein, 2009). In some ways, the first feeds into the second here.

'Overconfidence bias' has been widely noted by psychologists across individuals, including professionals. It is, in fact, so ubiquitous that noted psychologist and Nobel laureate Kahneman put it at the top of his list, when asked if there was one thing he could wish away, what would that be (Shariatmadari, 2015). This bias is very much evident in the field of adventure sports. Many novices in these adventure pursuits, who are just about beginning out, seem to exhibit 
these tendencies. While instructors may be prone to boosting their trainees' confidence by making things seem simple, many novices get taken in by these actions, and after a little experience, under tightly controlled conditions, actually begin to consider themselves as being 'in control'. This may be right under appropriate conditions, perhaps, close to ideal, but we really do not know how our world can change, literally, in seconds. (Weick, 1993, 1996) Besides, looked at in a way, ideal conditions too are rare, as it means many things coming together, just right (this is the Swiss Cheese Model argument in reverse) (Reason, 1998, as cited in Shrivastava, Sonpar \& Pazzaglia, 2009). The fields of normal accident theory and high reliability theory inform us how fragile is the operating consistency that humans and machines are able to achieve over an extended time duration (Perrow, 1984; Rijpma, 1997; Shrivastava, Sonpar, Pazzaglia, 2009; Weick, 1979/1969, 1993; Weick et al., 1999). Small things, such as a masking tape the aircraft's three static ports (Wrigley, 2018), or fatigue failure of engine fuse pin (FAA Lessons Learned, n.d.), may lead to disasters. In the air, during either skydive or powered flight, for example, many things can happen that may be difficult to predict and control. Similarly, many professionals and organizations are observed to display a lack of planning for contingencies, e.g., accidents and worse. (Kahneman \& Klein, 2009; Perrow, 1984; Shrivastava, Sonpar, Pazzaglia, 2009; Weick, Sutcliffe, \& Obstfeld, 1999) Fortunately, here we can learn from the military, where planning for contingencies is almost a given. Every commander, even while planning and hoping for the best case scenario, also thinks and plans for a range of "what if' scenarios. Good 'special forces' teams are able to operate in an orchestrated manner over a range of such scenarios, as this gets built-in them while operating together over a period of time. At the individual level, I have described this to some extent where I recollect my own preparation for a parachute jump. It would help those starting out new on any such tasks to think 
of the various contingencies relevant to the scenario and the available options beforehand. Read, discuss and inform one-self beforehand, so that one is better prepared. This will also lead to mental alertness, e.g., as in counting off, "One thousand, two thousand, ..." to keep time up to deployment of the main chute; if nothing happens by the count of "five thousand", one just knows what to do from previous training, reflection and preparation.

The importance of practice and rehearsals is often ignored and not given due attention. Recent advances in computers and automation have had the effect of automating many processes, with the attendant lowering of preparedness and a false sense of dependence on various redundancies built into our organizations and systems. This phenomenon has been acknowledged to have led to some fatal accidents in civil aviation sector in the recent times, where young pilots were not able to decipher what had gone wrong - so total was their dependence on computers and instruments that they weren't able to take preventive action to come out of some well-known and basic flying emergencies. (e.g., Air France Flight 447 [Wise, 2011] and Air Asia Flight 8501 crashes [Otto \& Pasztor, 2015])

\section{Learning With an Open Mind}

As we have seen above, learning is a key facet, all through. There is so much for one to learn in order to more deeply understand the environment which one is stepping into. So, one needs to be open to interaction, so as to learn from others' experiences as also from the accumulated wisdom that's around. Additionally, one must question everything in this process, because it is your life at stake and things should make sense to you. Practice drills and rehearse contingencies in your mind and on ground. Acknowledge the mistakes you make and learn from 
them. Could you have done better? How would that have been possible? Think back and begin over again.

The history of accidents, in both NAT and HRT literatures, presents another perspective — one of innumerable near-misses — unfortunately, wherefrom correct lessons were not drawn. Even at cutting-edge organizations, such as, NASA, many of the lessons of Challenger disaster (Starbuck, and Milliken, 1988; Vaughan, 1997) were ignored by the time Columbia disaster occurred (Starbuck \& Farjoun, 2005). Near misses of the kind were not reported, such as ones that eventually led to the friendly-fire incident wherein two US F-15 fighters misidentified two US helicopters as Iraqi Mi-24 "Hind" helicopters and shot both down on 14 April 1994 (Snook, 2000). In our organizational and professional circles, there is dire need for suitable avenues to disclose such "near misses" in an environment of psychological safety; that would lead to many more conversations and interactions that could, in turn, help warn others about what to watch out for - such that, something that is deemed 'not possible', would become 'yet feasible' now. In this manner, it would facilitate use of past mistakes, or even near-misses, as opportunities for forward learning and avoid making mistakes leading to disasters.

Yet another, forward-looking preventive mechanism, as seen above, is applying others' experiences and learning to one's own situations, much as they may seem different at first glance. The Powerchute flying accident was preventable, with good forward planning and orientation, learning more about the applying parameters in a changed operating scenario, and from hazards faced by much bigger aircrafts in those typical environments. However, as we saw, our biases carried the day and we came out loser there. 


\section{Role of Intuition in the Above Experiences}

Many a times, decision makers refer to intuition as the mysterious guiding characteristic for their decisions; however, as then Indian cricket team captain M. S. Dhoni's explanation of his intuition indicates, we need to delve further into the underlying bases, as described above (The Times of India, 2014). I have covered this aspect earlier, and I will just state that intuition is based on deep-domain knowledge and developed over a long period of time, through constant learning; so, I would not claim this plays any part in my accounts above. It could, however, be relevant in the case of experienced sky-divers with a few thousands of skydives under their belt, provided they were operating in an environment closely similar to where their experience had been acquired. So, mindfulness and sensemaking, rather than intuition, is more relevant in case of professionals who are still working on their way to acquiring expertise.

\section{Conclusion}

In this self-reflective analysis, I have described some personal experiences from the field of adventure sports that fell in the category of high-risk, critical decisions, involving split-second choices. I tried to trace the mental cognitive processes through these critical incidents from a decision maker's perspective. The graphic description aimed to present a ring-side view of the decisive seconds. These descriptions were analyzed and built upon to establish a practitioner's functional framework of high-risk, critical decision scenarios, while drawing upon established theories and frameworks from cognitive and psychological decision research. In doing so, I have also given a practical tinge to these applicable theories for practitioners in field. Hopefully, this offers some insights to professionals from other domains, who too may be called upon to make similar decisions under crisis scenarios. 


\section{REFERENCES}

Araujo, D., Davids, K., \& Hristovski, R. 2006. The ecological dynamics of decision making in sport. Psychology of Sport and Exercise, 7(6), 653-676.

Bar-Eli, M., \& Raab, M. 2006. Judgment and decision making in sport and exercise: Rediscovery and new visions. Psychology of Sport and Exercise, 7 (6) 519-524.

Barnard, C.I. 1938. The functions of the executive. Cambridge: Harvard University Press.

Bennis, W. M., \& Pachur, T. 2006. Fast and frugal heuristics in sports. Psychology of Sport and Exercise, 7(6), 611-629.

Burke, B. 2013a. The horizontal flight problem. Dropzone.com. Accessed on 15 January 2016:

http://www.dropzone.com/safety/General_Safety/The_Horizontal_Flight_Problem_935.ht $\underline{\mathrm{ml}}$

Burke, B. 2013b. Implications of recent tracking, tracing and wingsuit incidents. Dropzone.com. Accessed on 15 January 2016:

http://www.dropzone.com/safety/General_Safety/Implications_of_Recent_Tracking_Traci ng and Wingsuit Incidents $938 . \mathrm{html}$

Campbell, D. 2019. The many human errors that brought down the Boeing 737 Max. The Verge. Accessed on 15 June 2020: https://www.theverge.com/2019/5/2/18518176/boeing-737max-crash-problems-human-error-mcas-faa

Chase, W. G., \& Simon, H. A. 1973. Perception in chess. Cognitive Psychology, 4(1), 55-81.

Cohen, L., Duberley, J., \& Musson, G. 2009. Work-life balance? An autoethnographic exploration of everyday home-work dynamics. Journal of Management Inquiry, 18(3), 229-241. Cited in Rowe, O'Brien, Rouse, \& Nixon, 2011.

Dane, E., \& Pratt, M. G. 2007. Exploring intuition and its role in managerial decision making. Academy of Management Review, 32(1), 33-54.

Elmes, M., \& Barry, D. 1999. Deliverance, denial, and the death zone: a study of narcissism and regression in the May 1996 Everest climbing disaster. The Journal of Applied Behavioral Science, 35(2), 163-187.

Elmes, M., \& Frame, B. 2008. Into hot air: a critical perspective on Everest. Human Relations, 61(2), 213-241.

Federal Aviation Administration (FAA) Lessons Learned, n.d. El Al Flight 1862, Boeing $747-$ 200F, 4X-AXG, 1992. Accessed on 15 May 2020:

https://lessonslearned.faa.gov/l1 main.cfm?TabID=3\&LLID=38\&LLTypeID $=0$.

Flanagan, J. C. 1954. The critical incident technique. Psychological Bulletin, 51(4), 327-358.

Gigerenzer, G., Todd, P.M., \& the ABC Research Group 1999. Simple heuristics that make us smart. NY: Oxford University Press.

Gobet, F., \& Simon, H. A. 1996. The roles of recognition processes and look-ahead search in time-constrained expert problem solving: Evidence from grand-master-level chess. Psychological Science, 52-55.

Johnson, J. G. 2006. Cognitive modeling of decision making in sports. Psychology of Sport and Exercise, 7(6), 631-652.

Kahneman, D. 2011. Thinking, fast and slow. Farrar, Straus, and Giroux, NY.

Kahneman, D., \& Tversky, A. 1979. Prospect theory: an analysis of decision under risk. Econometrica, 47(2), 263-291. 
Kahneman, D., \& Tversky, A. 1984. Choices, values, and frames. American Psychologist, 39(4), 341-350.

Kahneman, D., \& Klein, G. 2009. Conditions for intuitive expertise: a failure to disagree. American Psychologist, 64(6), 515.

Kayes, D. C. 2004. The 1996 Mount Everest climbing disaster: The breakdown of learning in teams. Human Relations, 57(10), 1263-1284.

Klein, G. A., Calderwood, R., \& Clinton-Cirocco, A. 1986, September. Rapid decision making on the fire ground. In Proceedings of the Human Factors and Ergonomics Society Annual Meeting (Vol. 30, No. 6, pp. 576-580). SAGE Publications.

Koehler, D. J., \& Harvey, N. (Eds.) 2004. Blackwell handbook of judgment and decision making. Malden, MA: Blackwell.

Kolb, D.A. 1974. Learning and problem solving: On management and the learning process. In D.A. Kolb, I.M. Rubin \& J.M. McIntyre, Organizational psychology: A book of readings, 2nd ed.: 27-42. Englewood Cliffs, NJ: Prentice-Hall, Inc.

Kolb, D. A. 1984. Experiential learning: experience as the source of learning and development. Englewood Cliffs, NJ: Prentice-Hall.

Langer, E. J. 1989. Mindfulness. Addison-Wesley/Addison Wesley Longman.

Langer, E. J., \& Moldoveanu, M. 2000. The construct of mindfulness. Journal of Social Issues, 56(1), 1-9.

Lipshitz, R., Klein, G., Orasanu, J., \& Salas, E. 2001. Taking stock of naturalistic decision making. Journal of Behavioral Decision Making, 14(5), 331-352.

March, J. G. 1997. Understanding how decisions happen in organizations. In, Z. Shapira (ed.), Organizational Decision Making, 9-32. Cambridge: Cambridge University Press.

March, J. G., \& Simon, H. A. 1958a. Organizations. New York, NY: John Wiley \& Sons, Inc. Pp. 262.

March, J. G., \& Simon, H. 1958b. A behavioral theory of decision making. Personnel Administration, 21(3), 8-10.

Marewski, J. N., Gaissmaier, W., \& Gigerenzer, G. 2010. Good judgments do not require complex cognition. Cognitive Processing, 11(2), 103-121.

Meehl, P. E. 1954. Clinical versus statistical prediction. Minneapolis: University of Minnesota Press.

Meehl, P. E. 1986. Causes and effects of my disturbing little book. Journal of Personality Assessment, 50(3), 370-375.

Mintzberg, H. 1973. The nature of managerial work. New York: Harper \& Row. Pp. 298.

Mintzberg, H., Raisinghani, D., \& Theoret, A. 1976. The structure of" unstructured" decision processes. Administrative Science Quarterly, 246-275.

Neumann, J. V., \& Morgenstern, O. 1944. Theory of games and economic behavior. Princeton: Princeton university press.

Otto, B., \& Pasztor, A. 2015. Malfunctions, pilot response blamed in AirAsia Flight 8501 Crash. The Wall Street Journal, 1 Dec. 2015. Accessed on 24 July 2016:

http://www.wsj.com/articles/rudder-system-failure-contributed-to-airasia-flight-8501crash-1448956384.

Perrow, C. 1984. Normal accidents: living with high risk technologies. New York: Basic Books. Reason, J. 1998. Achieving a safe culture: theory and practice. Work \& Stress, 12(3), 293-306. 
Rijpma, J. A. 1997. Complexity, tight-coupling and reliability: Connecting normal accidents theory and high reliability theory. Journal of Contingencies and Crisis Management, 5(1), $15-23$

Roberto, M. A. 2002. Lessons from Everest: the interaction of cognitive bias, psychological safety, and system complexity. California Management Review, 45(1), 136-158.

Rochlin, G. I. 2011. How to hunt a very reliable organization. Journal of contingencies and crisis management, 19(1), 14-20.Rochlin, G.I., La Porte, T.R., \& Roberts, K.H. 1987. The selfdesigning high-reliability organization: Aircraft carrier flight operations at sea. Naval War College Review, 40(4), 76-92.

Rowe, W. G., O'Brien, J., Rouse, M. J., \& Nixon, R. D. 2011. Navy stories: behavior versus professional control. Journal of Management Inquiry, 1056492611400751.

Shariatmadari, D. 2015. Daniel Kahneman: 'What Would I Eliminate If I Had a Magic Wand? Overconfidence.'. The Guardian, Saturday, 18 July 2015. Accessed on 6 February 2016: http://www.theguardian.com/books/2015/jul/18/daniel-kahneman-books-interview.

Shrivastava, S., Sonpar, K., \& Pazzaglia, F. 2009. Normal accident theory versus high reliability theory: a resolution and call for an open systems view of accidents. Human Relations, 62(9), 1357-1390.

Simon, H. A. 1947. Administrative behavior: a study of decision-making processes in administrative organization (1st ed.). New York: Macmillan.

Simon, H. A. 1955. A behavioral model of rational choice. The Quarterly Journal of Economics, 99-118.

Simon, H. A. 1959. Theories of decision-making in economics and behavioral science. The American Economic Review, 49(3), 253-283.

Simon, H. A. 1979. Rational decision making in business organizations. The American Economic Review, 69(4), 493-513.

Simon, H. A. 1987. Making management decisions: the role of intuition and emotion. The Academy of Management Executive, 1(1): 57-64.

Snook, S.A. 2000. Friendly fire. Princeton University Press.

Starbuck, W.H., and Milliken, F.J. (1988). Challenger: fine-tuning the odds until something breaks. Journal of Management Studies, 25: 319-340.

Starbuck, W.H., \& Farjoun, M. (Eds.) 2005. Organization at the limit: lessons from the Columbia disaster. John Wiley \& Sons.

Tempest, S., Starkey, K., \& Ennew, C. 2007. In the death zone: a study of limits in the 1996 Mount Everest disaster. Human Relations, 60(7), 1039-1064.

The Times of India 2014. My gut feeling guides me: MSD. The Times of India, 8 July 2014.

Tversky, A., \& Kahneman, D. (1973). Availability: a heuristic for judging frequency and probability. Cognitive Psychology, 5(2), 207-232.

Vaughan, D. 1997. The Challenger launch decision: risky technology, culture, and deviance at NASA. University of Chicago Press.

Weick, K.E. 1979 (1969). The social psychology of organizing. Reading, Mass.: AddisonWesley.

Weick, K. E. 1993. The collapse of sensemaking in organizations: the Mann Gulch disaster. Administrative Science Quarterly, 628-652.

Weick, K. (1996). Prepare your organization to fight fires. Harvard Business Review, May-June: 3-6. 
Weick, K. E., \& Putnam, T. 2006. Organizing for mindfulness eastern wisdom and western knowledge. Journal of Management Inquiry, 15(3), 275-287.

Weick, K. E., \& Sutcliffe, K. M. 2006. Mindfulness and the quality of organizational attention. Organization Science, 17(4), 514-524.

Weick, K.E., Sutcliffe, K.M., \& Obstfeld, D. 1999. Organizing for high reliability: processes of collective mindfulness. In, R. Sutton \& B. Staw (eds.), Research in Organizational Behavior, 81-123. Greenwich, CT: JAI.

Wharton Leadership Ventures (n.d.). https://leadership.wharton.upenn.edu/leadership-ventures-2/

Wise, J. 2011. What really happened aboard Air France 447. Popular Mechanics, 6 Dec. 2011. Accessed on 24 Dec. 2013: http://www.popularmechanics.com/flight/a3115/what-reallyhappened-aboard-air-france-447-6611877/.

Wrigley, S. 2018. "It must be fictitious!" Aeroperu 603. Accessed on 15 May 2020:

https://fearoflanding.com/accidents/accident-reports/it-must-be-fictitious-aeroperu-603/. 
Table 1

\begin{tabular}{|l|l|}
\hline \multicolumn{1}{|c|}{$\begin{array}{c}\text { Key Factors during High-Risk Critical } \\
\text { Decision making }\end{array}$} & \multicolumn{1}{|c|}{$\begin{array}{c}\text { Critical Incident Code(s) } \\
\text { Mapped }\end{array}$} \\
\hline Good drills and practice & A, B, C, E, F \\
\hline Deep domain knowledge & All (A to F) \\
\hline Being prepared, "Mindfully" & B, C, D, E \\
\hline $\begin{array}{l}\text { Planning and preparedness for contingencies } \\
\text { and options }\end{array}$ & B, C, D, F \\
\hline Learning with an open mind & A, B, D \\
\hline
\end{tabular}

Legend: Critical Incident Codes

\begin{tabular}{|l|c|}
\hline \multicolumn{1}{|c|}{ Critical Incident } & Critical Incident Code \\
\hline $\begin{array}{l}\text { Initiation and overview (Training } \\
\text { drills) }\end{array}$ & $\mathrm{A}$ \\
\hline $\begin{array}{l}\text { Main-chute full malfunction during } \\
\text { parachuting (in-situ causal analysis } \\
\text { and response) }\end{array}$ & $\mathrm{B}$ \\
\hline $\begin{array}{l}\text { Main-chute partial malfunction } \\
\text { during skydiving (in-situ causal } \\
\text { analysis and response) }\end{array}$ & $\mathrm{C}$ \\
\hline $\begin{array}{l}\text { Powerchute flying flight emergency } \\
\text { (factors leading upto and response) }\end{array}$ & $\mathrm{D}$ \\
\hline $\begin{array}{l}\text { Parachute jump after recovery } \\
\text { (preparation and execution) }\end{array}$ & $\mathrm{E}$ \\
\hline $\begin{array}{l}\text { Account of a mid-air parachute air- } \\
\text { accident (action of deployment of } \\
\text { reserve chutes) }\end{array}$ & $\mathrm{F}$ \\
\hline
\end{tabular}

Table 1: Mapping Learning Highlights of Critical Incidents with Lessons for Decision making from High-Risk Adventure 
Figure 1
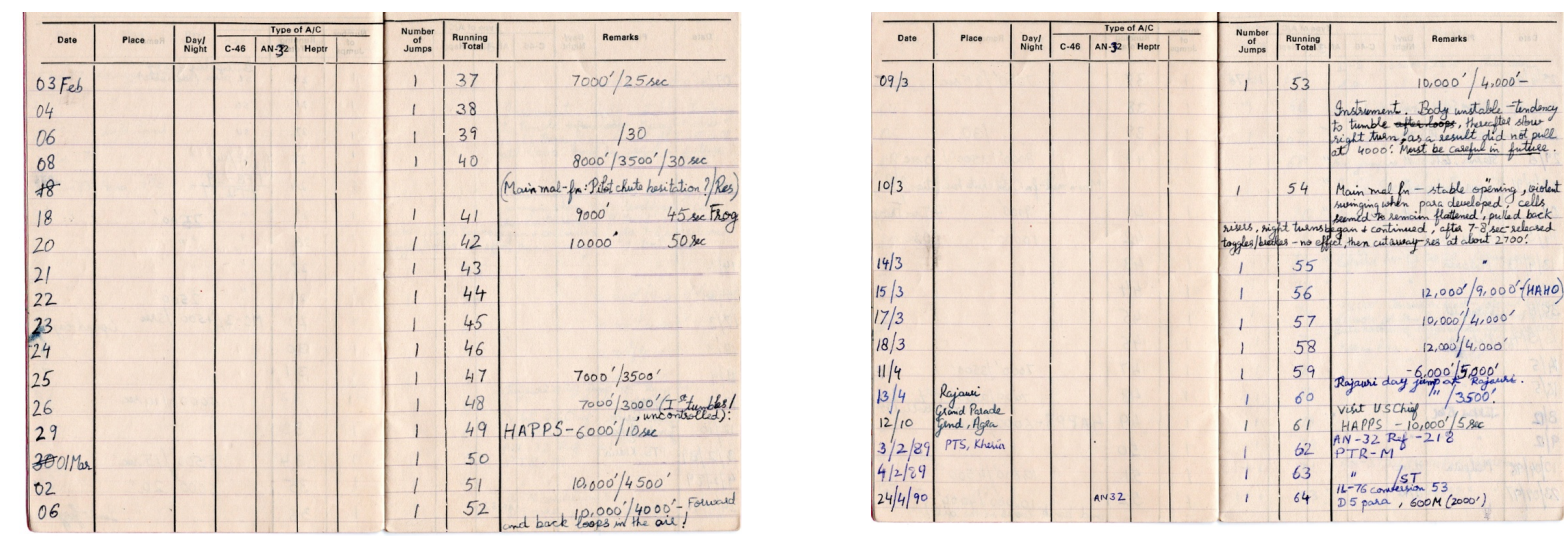

Figure 1: Extracts from jump log-book, with learning experiences scribbled alongside.

Figure 2

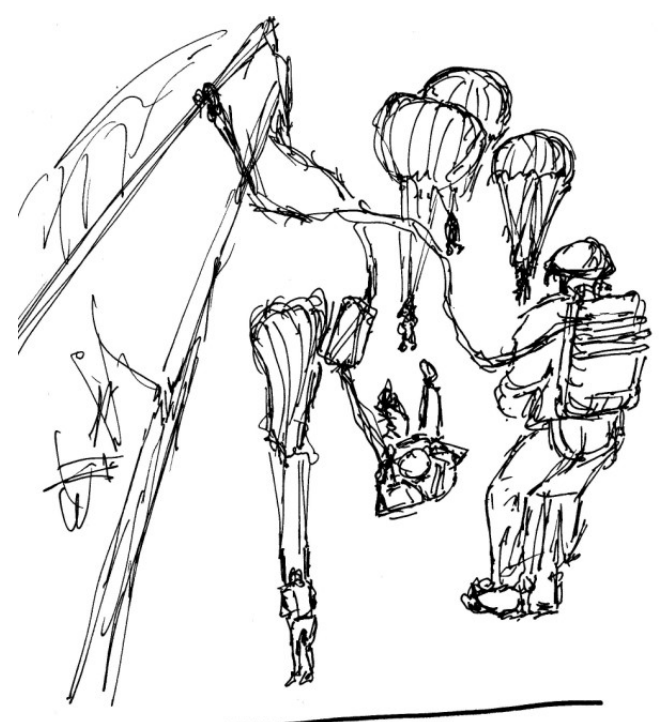

Figure 2: Static-line jump from a helicopter's rear-exit.

One can see the sequence of opening of the parachute, beginning with the jumper closest to the door, who has just taken the leap into the void below, with the body tucked in. Other figures show the deployment of the parachute and its opening. 
Figure 3
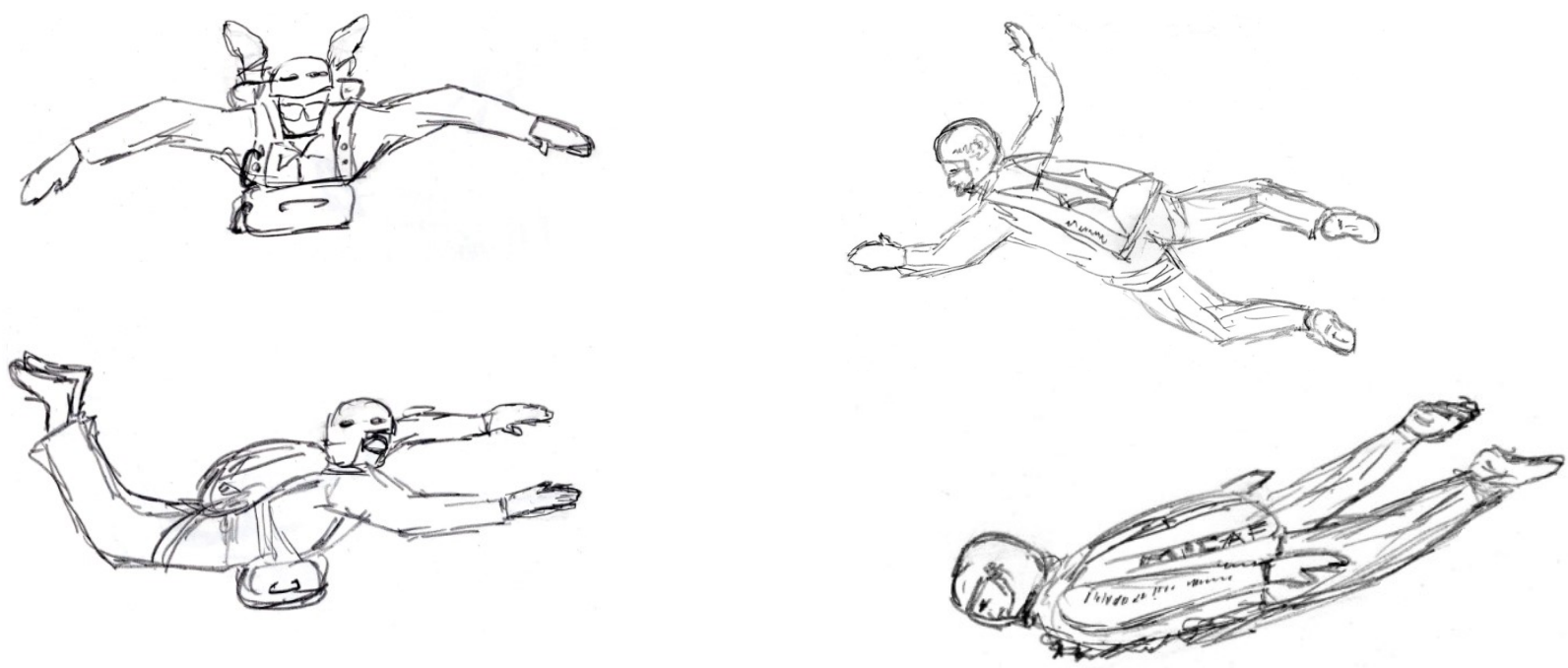

Figure 3: Common positions of a Skydiver while free-falling through the air.

The first three skydivers show the spread-eagle position, which is the most stable position adopted by a skydiver while falling. It presents the maximum surface area falling downward and hence the slowest free-fall speeds of about $120 \mathrm{mph}$ (about 5.6 seconds every 1000 feet). The skydiver can head or turn towards right or left by extending out or pulling in the right and the left hand together - quite akin to driving, as it were, once you get a feel of it.

The last skydiver is in a diving (Delta track) position, with the arms to the side and pushed back past the body - to speed up the vertical descent, while heading in the forward direction. 


\section{Figure 4}
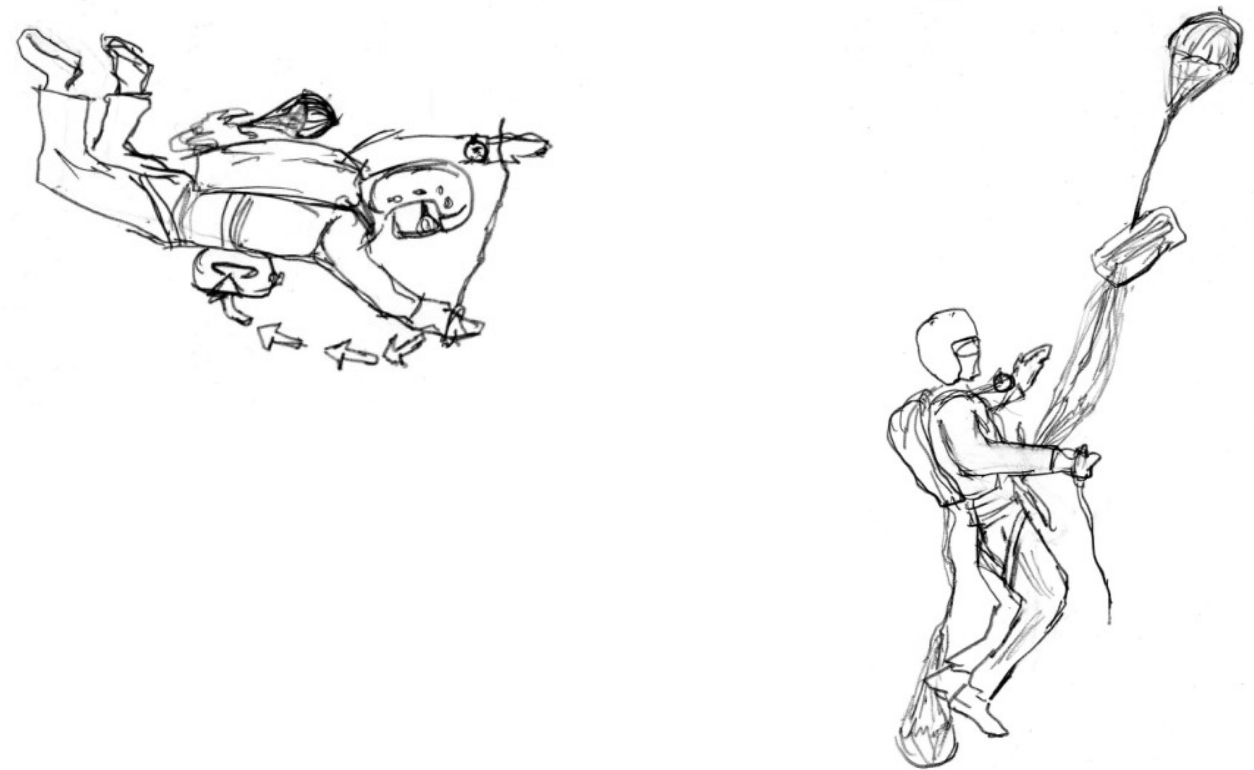

Figure 4: Round-canopy Malfunction incident.

Having pulled on my main parachute rip-cord (seen in the right hand to the left), I could not feel the pull on my back, due to pilot-chute malfunction (which can be seen atop my parachute bag). I then moved to pull at the reserve rip-cord handle in front of my stomach (shown by the arrows). The reserve parachute can then be seen opening to the right.

\section{Figure 5}
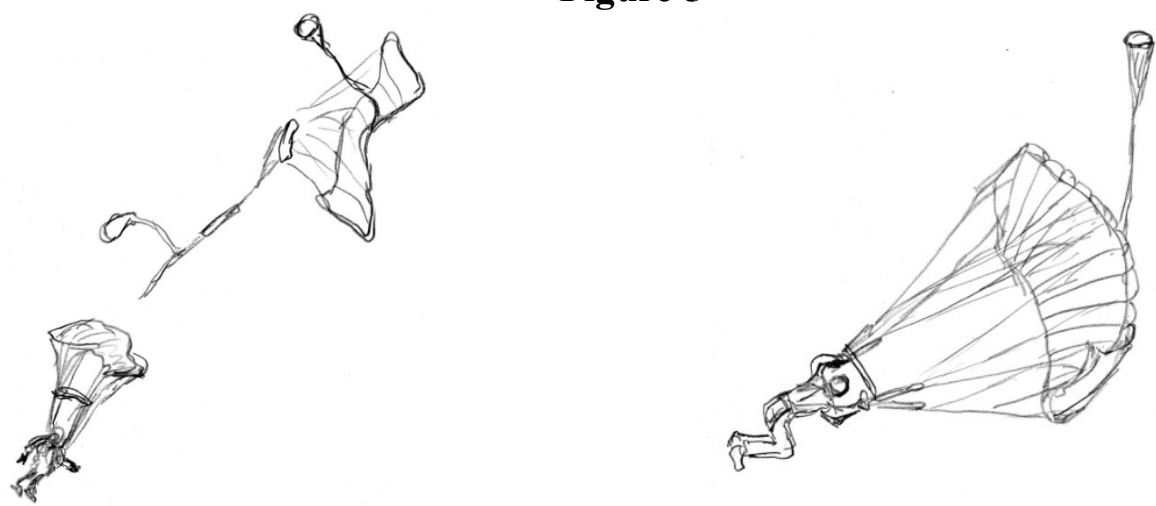

Figure 5: Square-canopy Malfunction incident.

As I pulled away at the main-chute's cut-away handle, it can be seen separating above and away from me (left), while the reserve-chute begins to deploy, as it is activated automatically; coming down on the reserve-chute (right). 
Figure 6
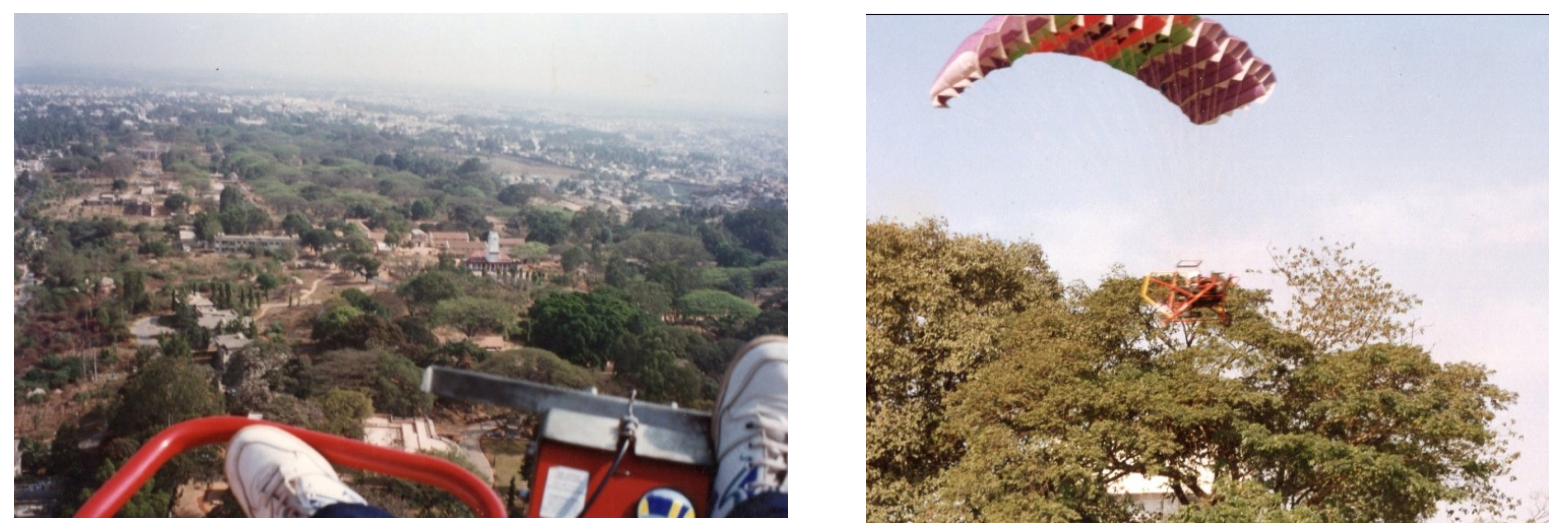

Figure 6: Powerchute flying.

View from a Powerchute in flight (left); coming in for a landing (right).

\section{Figure 7}
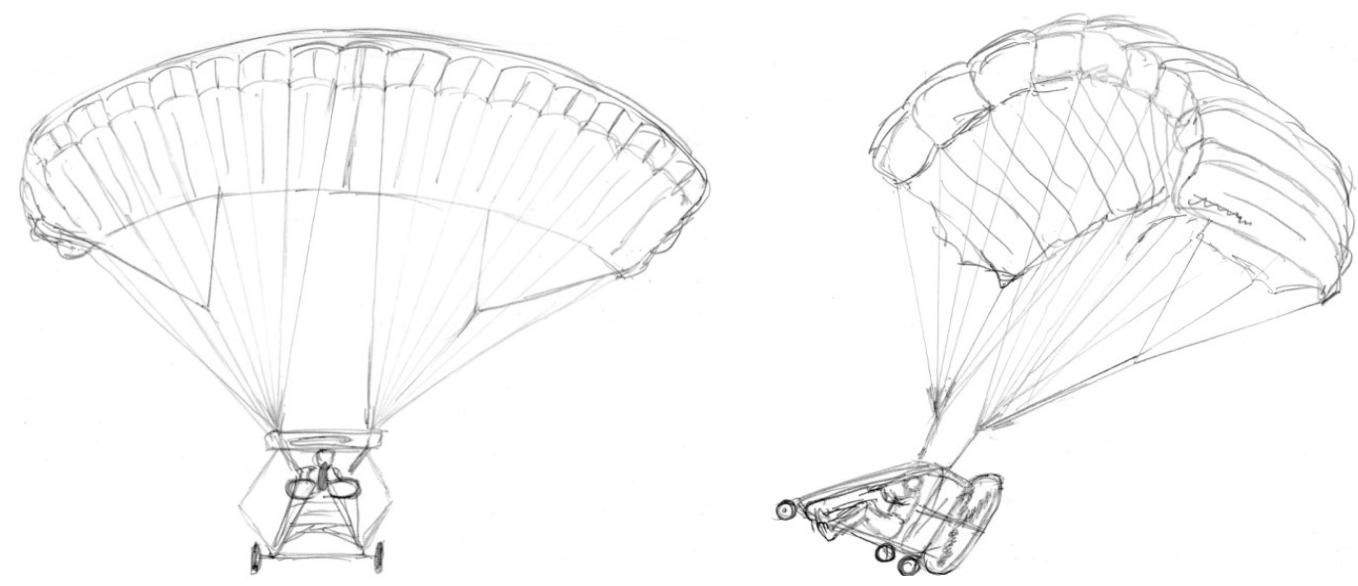

Figure 7: Powerchute in flight.

Frontal- (left) and side-view (right) during flight. Note the attitude of the machine, which is weighted forward due to the engine mounted on the trike, with the wings trailing behind. 